\title{
Differential Expression of miR-101 and miR-744 in Nasopharyngeal Carcinoma in Pahang State of Malaysia ${ }^{\dagger}$
}

\author{
Azmir AHMAD ${ }^{1,5}$, Haziq Abdul WAHID ${ }^{1}$, Wan Ishlah LEMAN ${ }^{2}$, \\ Noor Syamila OTHMAN ${ }^{1}$, Azlina Abdul RAHMAN ${ }^{3}$, Kahairi ABDULLAH ${ }^{2}$, \\ Siti Aesah Naznin MUHAMMAD ${ }^{4}$ and Mohd. Arifin KADERI ${ }^{1, *}$
}

\author{
${ }^{I}$ Department of Biomedical Science, Kulliyyah of Allied Health Sciences, International Islamic University \\ Malaysia, Jalan Sultan Haji Ahmad Shah, Bandar Indera Mahkota, Pahang, Malaysia \\ ${ }^{2}$ Department of Otorhinolaryngology-Head and Neck Surgery, Kulliyyah of Medicine, International \\ Islamic University Malaysia, Jalan Sultan Haji Ahmad Shah, Bandar Indera Mahkota, Pahang, Malaysia \\ ${ }^{3}$ Department of Pathology, Hospital Tengku Ampuan Afzan, Jalan Tanah Putih, Pahang, Malaysia \\ ${ }^{4}$ Department of Pathology and Laboratory Medicine, Kulliyyah of Medicine, International Islamic \\ University Malaysia, Jalan Sultan Haji Ahmad Shah, Bandar Indera Mahkota, Pahang, Malaysia \\ ${ }^{5}$ Department of Basic Medical Science for Nursing, Kulliyyah of Nursing, International Islamic \\ University Malaysia, Jalan Sultan Haji Ahmad Shah, Bandar Indera Mahkota, Pahang, Malaysia
}

('Corresponding author's e-mail: ariffink@iium.edu.my)

Received: 7 March 2018, Revised: 20 July 2018, Accepted: 26 August 2018

\begin{abstract}
Previous study found that microRNA-101 (miR-101) and microRNA-744 (miR-744) were deregulated in head and neck cancers and were implicated in nasopharyngeal carcinoma (NPC) carcinogenesis. Thus, this study aimed to determine the expression of miR-101 and miR-744 in NPC and analyse the utility of these microRNAs (miRNAs) as diagnostic biomarkers. Total RNA was extracted from 31 NPC and 7 non-NPC control formalin-fixed paraffin-embedded (FFPE) samples. Complementary DNA (cDNA) was synthesized from the total RNA and proceeded with quantitative real-time polymerase chain reaction. Differential expression of miR-101 and miR-744 were calculated from quantification cycle $(\mathrm{Cq})$ data using $2^{-\Delta \Delta \mathrm{Cq}}$ calculation. The performance of these miRNAs were calculated using receiver operating characteristic (ROC) curve analysis. The differential expression for miR-101 and miR744 were $-1.39(\mathrm{p}<0.05)$ and $2.48(\mathrm{p}>0.05)$, respectively, where the deregulations were consistent with the previous report. The area under curve for miR-101, miR-744 and combination of miR-101 and miR744 were 0.654 (95 \% CI: 0.465 - 0.844), 0.588 (95\% CI: 0.368 - 0.808) and 0.626 (95\% CI: 0.481 0.771), respectively. However, re-analysis using balanced sample size between NPC and non-NPC control group showed the value decreased to 0.653 (95\% CI: $0.347-0.959)$ for miR-101 but increased to 0.827 (95\% CI: $0.601-1.000)$ for miR-744 and 0.758 (95\% CI: $0.576-0.939)$ for the combination of miR-101 and miR-744, indicating the importance of having a balanced sample size. We have successfully determined the expression of miR-101 and miR-744 in NPC samples. We also demonstrated statistically the utility of these miRNAs as diagnostic biomarkers.
\end{abstract}

Keywords: Nasopharyngeal carcinoma, miR-101, miR-744, differential expression, diagnostic biomarker

\footnotetext{
${ }^{\dagger}$ Presented at the International Conference on Biomedical Sciences 2018: March 22 ${ }^{\text {nd }}-23^{\text {rd }}, 2018$
} 
http://wjst.wu.ac.th

\section{Introduction}

Nasopharyngeal carcinoma (NPC) is the fifth most common cancer in terms of incidence and prevalence in Malaysia after breast, colorectal, lung and lymphoma cancers. Epidemiologically, a recent report revealed that males of ethnic Chinese within the range of 25 to 65 years old were at the highest risk of NPC, followed by Malays and Indians [1]. The same authors also reported that the prevalence rate of NPC in the Malaysian Chinese was only slightly lower than that of the Southern China and Singaporean Chinese populations, in respective orders. Previously, Devi et al. [2] have reported a surprisingly high prevalence of NPC among Bidayuh native group in Sarawak, where the prevalence was the highest rate recorded by worldwide population-based registry between years of 1996 until 1998. In years of 2003 until 2005, 2315 cases of NPC were reported in Malaysia, and it was the seventh common cancer in the country and the second highest rate of NPC internationally [3]. Even though the evidences demonstrate that the prevalence of NPC in Malaysia is at alarming level, the number of published studies on NPC among Malaysian is still scarce and at fundamental level.

MicroRNAs (miRNAs) are a new class of non-coding RNAs that regulate the expression of messenger RNAs (mRNAs) by post-transcriptional inhibition or degradation of the mRNAs [4]. Various miRNAs are involved in the regulation of physiological cellular development such as cell growth, proliferation, differentiation, and apoptosis [5]. In cancer, miRNA can be divided according to their functionality into tumor suppressive, oncogenic, and viral miRNAs, depending on their functions in mechanisms of oncogenesis and tumor progression [6-8]. Several studies have been performed to screen and determine the roles of miRNAs in NPC. A review on miRNAs in NPC reported a list of miRNAs encoded in human and Epstein-Barr virus (EBV) that may involve in the carcinogenesis of NPC [9]. The down- and up-regulation of tumor suppressive and carcinogenic miRNAs, respectively, are involved in the carcinogenesis of NPC by increasing the cellular proliferation [10], reducing the cellular apoptosis [11], and promoting the NPC cell migration and invasion [12] through the deregulation of various gene expression such as $C$ - $X$-C chemokine receptor type 4 (CXCR4), enhancer of zeste homolog 2 (EZH2) and $T$ cell lymphoma invasion and metastasis 1 (TIAM1), respectively. Additionally, certain miRNAs such as miR-29c may cause the NPC cells to develop resistance against radiotherapy and chemotherapy [13]. Meanwhile, viral miRNAs, particularly that of the EBV, play roles in several mechanisms to cause carcinogenesis of NPC in human such as manipulation of host genes that are responsible for apoptosis and immune response [14,15], and enhancing the migration and invasion of NPC cells [16].

miR-101 and miR-744 are the tumor-suppressive and oncogenic miRNAs that have been found to be involved in the carcinogenesis of NPC [17,18]. The role of miR-101 as a tumor suppressor in several cancers has been demonstrated by Chen et al. [19], where it can sensitize non-small cell lung cancer cells toward radiation. In NPC, Alajez et al. [20] demonstrated the role of miR-101 in causing cytotoxicity towards NPC cells upon ionizing radiation by regulating EZH2. The role of miR-101 in inducing sensitization of NPC towards radiation had been further demonstrated by Sun et al. [21], in which the ectopic miR-101 in NPC was found to sensitize the NPC cells towards radiation by targeting stathmin 1 (STMN1). In a recent study by Tang et al. [18] another role of miR-101 in inhibiting metastasis and angiogenesis in NPC was postulated through the regulation of integrin subunit alpha 3 (ITGA3). Meanwhile, the role of miR-744 as an oncogenic miRNA has been implicated in a study by Fang et al. [22], where they found that miR-744 caused NPC progression and metastasis by regulating Rho GTPase activating protein 5 (ARHGAP5). A later study found that c-Jun induce the up-regulation of miR-744 in NPC cells which then promoted the migratory and invasive ability of the cells [17], indicating the consistency with previous study in miRNA-mediated carcinogenesis of NPC.

A study by Nurul-Syakima et al. [25] found a list of miRNAs that were deregulated in a cohort of Malaysian head and neck squamous cell carcinoma (HNSCC) biopsy samples where NPC was included in the study sample population. In the study, the expression of miR-101 was found to be down-regulated, while miR-744 was up-regulated in HNSCC as compared to normal biopsies, which is consistent with findings in other NPC studies [18,21-23]. However, the study proceeded to solely focus on the role of miRNAs in the carcinogenesis of hypopharyngeal squamous cell carcinoma (HSCC) only and NPC was left out in the subsequent analyses. Based on our literature review, no other continuous or independent 
http://wjst.wu.ac.th

miRNA study had been previously done on NPC in Malaysia. This gap has motivated the current study to observe whether the differential expression of miR-101 and miR-744 in NPC samples would be the same as in the study by Nurul-Syakima et al. [25] and to evaluate the utility of these miRNAs as diagnostic biomarkers for NPC.

\section{Materials and methods}

\section{Sample collection}

The protocol of the study was reviewed and approved by IIUM Research Ethic Committee and Medical of International Islamic University Malaysia (IIUM) and Medical Research Ethic Committee of Ministry of Health, Malaysia. Formalin-fixed paraffin-embedded (FFPE) of nasopharynx biopsies were collected from archive of Department of Pathology of Hospital Tengku Ampuan Afzan (HTAA), Kuantan, Pahang, Malaysia. Thus, the study used convenience sampling due to the use of available and accessible samples only. The status of FFPE samples were verified by pathologists from HTAA. The samples with non-keratinizing differentiated and non-keratinizing undifferentiated tissues were categorized as NPC group and the samples with other than these tissues were categorized as non-NPC control group. In matching the NPC samples with non-NPC samples, some NPC samples have been paired non-NPC samples and some NPC samples have been matched with the non-NPC samples that were diagnosed with other type of diseases, such as lymphoma and inflammation. The summary of demographic data of the current study is provided in Table 1.

\section{Total RNA extraction}

The total RNA extraction was performed using innuPREP FFPE total RNA kit (Analytik Jena, Germany), according to the manufacturer's protocol. Briefly, 6 sections of $10 \mu \mathrm{m}$ thickness of FFPE samples were used for the total RNA extraction. The samples were treated with lysis solution and Proteinase $\mathrm{K}$ followed by incubation and centrifugation to obtain supernatant. The supernatant was subjected to spin column filtration and washing using wash buffer. Finally, the samples were eluted twice using $50 \mu \mathrm{L}$ RNase-free water. The purity and yield of RNA was quantified using NanoDrop ${ }^{\mathrm{TM}}$ spectrophotometer (Thermo Fisher Scientific, USA).

\section{Reverse transcription}

Reverse transcription reaction (RT) was performed using miScript PCR System (Qiagen, Germany). The starting material for template RNA was individually calculated for each sample to standardize the concentration across the samples up to $200 \mathrm{ng}$ template RNA per $20 \mu \mathrm{l}$ RT reaction according to the protocol. The master mixture was prepared by mixing $4 \mu \mathrm{l}$ of $5 \mathrm{x}$ miScript Hispec Buffer, $2 \mu \mathrm{l}$ of 10x miScript Nucleics Mix and $2 \mu \mathrm{l}$ of miScript Reverse Transcriptase in a $1.5 \mathrm{ml}$ tube. Later, RNase-free water and template RNA were added to the $8 \mu \mathrm{l}$ of total master mixture to make up the total reaction of reverse transcription to $20 \mu \mathrm{l}$ per sample. The mixture was incubated for at $37{ }^{\circ} \mathrm{C}$ for $60 \mathrm{~min}$, at $95{ }^{\circ} \mathrm{C}$ for $5 \mathrm{~min}$ to inactive the Reverse Transcriptase, and placed at $4{ }^{\circ} \mathrm{C}$ for infinity using CFX96 Real-Time System (Bio-Rad, USA). Then, the cDNA sample was diluted in $200 \mu$ l of RNase-free water prior to quantitative real-time polymerase chain reaction (qPCR).

\section{Quantitative real-time polymerase chain reaction}

The quantitative real-time polymerase chain reaction (qPCR) assays for miR-101 and miR-744 were prepared according to the protocol of miScript PCR System (Qiagen, Germany). This protocol enables quantification of mature miRNA by qPCR using target-specific miScript Primer Assay (forward primers) of miR-101 and miR-744 and the miScript SYBR Green PCR Kit containing miScript Universal Primer (reverse primer) and QuantiTect SYBR Green PCR Master Mix. Small nucleolar RNA 48 (SNORD48) was used as an endogenous control [25]. For each assay, the reaction mixture contained of $12.5 \mu 1$ QuantiTect SYBR Green PCR Master Mix, $2.5 \mu \mathrm{l}$ miScript Universal Primer, $2.5 \mu 1$ miScript Primer Assay for miR-101, miR-744 and SNORD48, $5 \mu$ l RNase-free water and $2.5 \mu 1$ template cDNA. The assay was then subjected to cycling condition according to the protocol using CFX96 Touch ${ }^{\text {TM }}$ Real-Time 
http://wjst.wu.ac.th

PCR Detection System thermocycler (Bio-Rad, USA). The $2^{-\Delta \Delta C t}$ method was used to calculate the foldchange of miR-101 and miR-744.

\section{Statistical analysis}

All statistical analyses were performed using IBM SPSS Statistics 2.0. The analyses to compare the mean between NPC and non-NPC control group was performed using independent $t$-test. The performance of miR-101 and miR-744 to distinguish between NPC cases from non-NPC controls was measured using receiver operating characteristic (ROC) curve analysis.

\section{Results and discussion}

Demographic data

As shown in Table 1, 31 cases of NPC were reported at HTAA. Out of these recruited cases, 25 patients $(80.65 \%)$ were males and $6(19.35 \%)$ were females. Malay patients constituted $19(61.29 \%)$ subjects of the cases, followed by $12(38.71 \%)$ from the Chinese ethnicity. Regarding stage at diagnosis, stage 4 was the most reported cases in HTAA, followed by stage 3, 2 and 1. Eight cases were marked as "unknown" status, due to unavailable hospital record for the stage of cancer at the diagnosis for these subjects. Regarding the specific type of the cancer, type 3, non-keratinizing undifferentiated NPC, was the most predominant type of NPC among the cases recruited in the study.

Table 1 Demographic data of subjects in NPC and non-NPC control group.

\begin{tabular}{lll}
\hline Characteristics & NPC & Non-NPC controls \\
\hline Number of subjects & 31 & 7 \\
Age (mean \pm SD) & $50.161 \pm 11.565$ & $45.714 \pm 12.855$ \\
Gender & 25 & 7 \\
Male & 6 & 0 \\
Female & & \\
Ethnic & 19 & 3 \\
$\quad$ Malay & 12 & 3 \\
Chinese & 0 & 1 \\
Aborigine & 1 & \\
Stage & 7 & \\
1 & 6 & \\
2 & 9 & \\
3 & 8 & \\
4 & & \\
Unknown & 3 & \\
Type & 28 & \\
2 & & \\
3 & & \\
\hline
\end{tabular}

\section{Quality control of the samples}

The status of the biopsies has been validated histologically by the pathologists from HTAA and IIUM. Out of 38 nasopharynx samples, 31 biopsies have been confirmed with NPC where 28 were nonkeratinized undifferentiated (type 3 NPC) and 3 were non-keratinized differentiated (type 2 NPC). All NPC biopsy samples contained at least $90 \%$ malignant tissues. Meanwhile, the other 7 biopsies were ascertained to be normal, lymphoma or inflammatory biopsies of nasopharynx.

The spectrometry result for total RNA extract of all samples is in Table 2. Most of the total RNA extracts were within the ideal range of nucleic acid purity level, except for certain sample extracts with 
http://wjst.wu.ac.th

slightly low purity, specifically NC12, C15, NPC18, NPC20 and NPC21. Even though these sample extracts have slightly low purity, the amplification curve of PCR reaction for these sample extracts did not show any abnormal curve, as shown in Figure 1, which indicated inhibition in the PCR reaction. Furthermore, we statistically compared the $\Delta \mathrm{Cq}$ values of miR-101 and miR-744 in poor and good purity sample extracts. The result, as shown in Table 3, showed there was no significant difference between $\Delta \mathrm{Cq}$ values of poor and good purity sample extracts. This indicated that there was no enzymatic inhibition that occurred in the qPCR reaction. Therefore, the use of slightly low purity of sample extracts in this study should have no significant confounding effect towards the downstream analysis.

Table 2 Data for quality control of the samples.

\begin{tabular}{|c|c|c|c|c|}
\hline \multirow{3}{*}{ Sample } & \multicolumn{3}{|c|}{ Spectrometry result } & \multirow{3}{*}{ Histological result } \\
\hline & \multicolumn{2}{|c|}{ Purity } & \multirow{2}{*}{ Concentration (ng/ $\mu \mathrm{l})$} & \\
\hline & $260 / 280$ & $260 / 230$ & & \\
\hline NC9 & 2.12 & 2.2 & 28.57 & Normal \\
\hline NN11 & 1.91 & 3.29 & 38.53 & Normal \\
\hline $\mathrm{NC} 12$ & 1.67 & 2.15 & 25.70 & Lymphoma \\
\hline $\mathrm{C} 4$ & 1.86 & 2.01 & 114.48 & Inflammation \\
\hline $\mathrm{C} 15$ & 1.75 & 2.10 & 199.49 & Normal \\
\hline $\mathrm{C} 16$ & 1.94 & 2.07 & 48.27 & Lymphoma \\
\hline $\mathrm{C} 29$ & 1.91 & 1.85 & 64.00 & Normal \\
\hline NPC1 & 1.82 & 2.09 & 148.96 & Nonkeratinized undifferentiated NPC \\
\hline NPC2 & 1.81 & 2.01 & 84.12 & Nonkeratinized undifferentiated NPC \\
\hline NPC3 & 1.92 & 2.05 & 171.41 & Nonkeratinized undifferentiated NPC \\
\hline NPC5 & 1.96 & 2.00 & 95.38 & Nonkeratinized undifferentiated NPC \\
\hline NPC6 & 1.85 & 2.14 & 112.20 & Nonkeratinized differentiated NPC \\
\hline NPC7 & 1.93 & 1.98 & 49.86 & Nonkeratinized undifferentiated NPC \\
\hline NPC8 & 1.92 & 1.85 & 231.87 & Nonkeratinized undifferentiated NPC \\
\hline NPC9 & 1.91 & 1.89 & 184.20 & Nonkeratinized undifferentiated NPC \\
\hline NPC10 & 2.00 & 1.90 & 141.72 & Nonkeratinized undifferentiated NPC \\
\hline NPC11 & 1.98 & 1.94 & 57.02 & Nonkeratinized differentiated NPC \\
\hline NPC12 & 1.89 & 2.02 & 145.98 & Nonkeratinized undifferentiated NPC \\
\hline NPC13 & 2.00 & 1.96 & 38.56 & Nonkeratinized undifferentiated NPC \\
\hline NPC14 & 1.88 & 2.04 & 107.31 & Nonkeratinized undifferentiated NPC \\
\hline NPC17 & 2.02 & 2.09 & 54.40 & Nonkeratinized undifferentiated NPC \\
\hline NPC18 & 1.98 & 1.79 & 86.91 & Nonkeratinized undifferentiated NPC \\
\hline NPC19 & 1.96 & 2.04 & 74.41 & Nonkeratinized undifferentiated NPC \\
\hline NPC20 & 1.96 & 1.71 & 87.87 & Nonkeratinized differentiated NPC \\
\hline NPC21 & 1.93 & 1.75 & 98.15 & Nonkeratinized undifferentiated NPC \\
\hline NPC22 & 1.99 & 1.99 & 663.61 & Nonkeratinized undifferentiated NPC \\
\hline NPC23 & 1.95 & 2.13 & 175.11 & Nonkeratinized undifferentiated NPC \\
\hline NPC24 & 1.97 & 1.92 & 107.89 & Nonkeratinized undifferentiated NPC \\
\hline $\mathrm{NPC} 25$ & 1.94 & 1.97 & 153.07 & Nonkeratinized undifferentiated NPC \\
\hline NPC26 & 1.96 & 2.10 & 165.68 & Nonkeratinized undifferentiated NPC \\
\hline NPC27 & 1.90 & 1.85 & 132.86 & Nonkeratinized undifferentiated NPC \\
\hline NPC28 & 1.87 & 2.26 & 36.89 & Nonkeratinized undifferentiated NPC \\
\hline NPC30 & 1.95 & 2.02 & 72.85 & Nonkeratinized undifferentiated NPC \\
\hline NPC32 & 1.92 & 1.97 & 52.08 & Nonkeratinized undifferentiated NPC \\
\hline NPC33 & 2.00 & 2.07 & 58.76 & Nonkeratinized undifferentiated NPC \\
\hline NPC34 & 1.90 & 2.00 & 229.15 & Nonkeratinized undifferentiated NPC \\
\hline NPC35 & 2.04 & 2.10 & 87.64 & Nonkeratinized undifferentiated NPC \\
\hline NPC36 & 1.98 & 2.07 & 167.33 & Nonkeratinized undifferentiated NPC \\
\hline
\end{tabular}



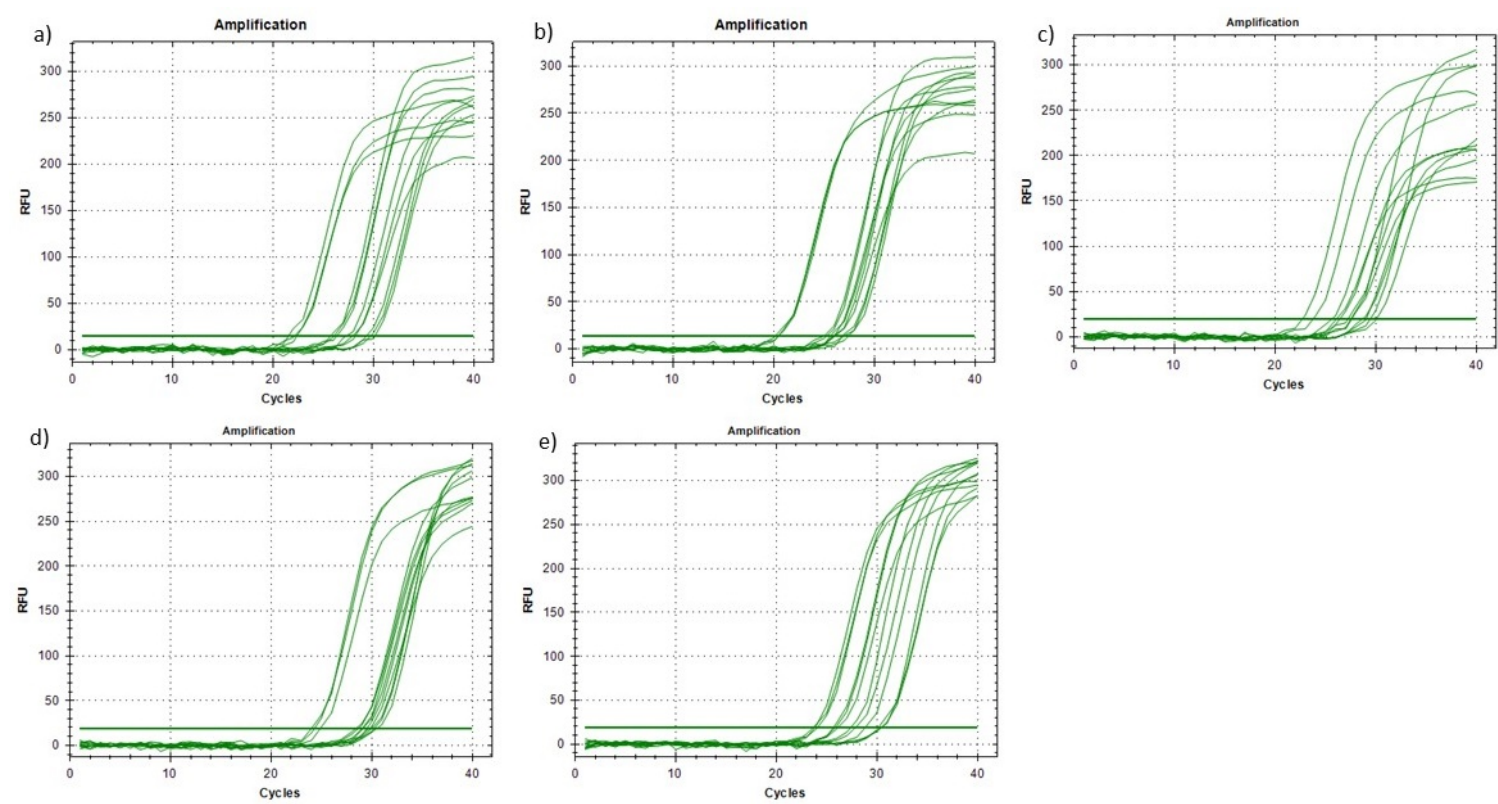

Figure 1 Amplification curves of miR-101, miR-744 and SNORD48 for sample extracts of a) NC12, b) C15, c) NPC18, d) NPC20 and e) NPC21.

Table $3 \Delta$ Cq values of miR-101 and miR-744 in poor and good quality sample extracts.

\begin{tabular}{|c|c|c|c|c|}
\hline Samples & $\Delta \mathrm{Cq}$ of miR-101 $($ mean $\pm \mathrm{SD})$ & p-value ${ }^{a}$ & $\Delta C q$ of miR-101 $($ mean \pm SD $)$ & p-value ${ }^{a}$ \\
\hline $\begin{array}{l}\text { Poor quality } \\
\text { sample extracts }\end{array}$ & $1.448 \pm 1.423$ & \multirow{2}{*}{0.836} & $1.406 \pm 0.971$ & \multirow[b]{2}{*}{0.553} \\
\hline $\begin{array}{l}\text { Good quality } \\
\text { sample extracts }\end{array}$ & $1.596 \pm 1.381$ & & $1.722 \pm 1.527$ & \\
\hline
\end{tabular}

${ }^{a} \mathrm{p}$-value based on independent $t$-test.

Differential expression of miR-101 and miR-744 in nasopharyngeal carcinoma as compared to non-NPC control subjects

The result for calculation of differential expression for miR-101 and miR-744 using $2^{-\Delta \Delta \mathrm{Cq}}$ method was depicted in Table 4. The calculation showed that our results were consistent with the finding by Nurul-Syakima et al. [25] where miR-101 was down-regulated and miR-744 was up-regulated in NPC as compared to non-NPC control group. However, only the down-regulation of miR-101 was statistically significant $(\mathrm{p}<0.05)$ but not the up-regulation of miR-744. 
http://wjst.wu.ac.th

Table 4 Differential expression of miR-101 and miR-744 in current and previous study.

\begin{tabular}{ccccc}
\hline Target & Fold-change in current study & p-value $^{\mathbf{a}}$ & Fold-change in previous study $^{\mathbf{b}}$ & p-value $^{\mathbf{a}}$ \\
\hline miR-101 & -1.39 & 0.039 & -0.51 & 0.0202 \\
miR-744 & 2.48 & 0.232 & 0.61 & 0.00264 \\
\hline
\end{tabular}

${ }^{a} \mathrm{p}$-value based on independent $t$-test.

${ }^{\mathrm{b}}$ AM Nurul-Syakima, C Yoke-Kqueen, AR Sabariah, MS Shiran, A Singh and L Learn-Han. Differential microRNA expression and identification of putative microRNA targets and pathways in head and neck cancers. Int. J. Mol. Med. 2011, DOI: 10.3892/ijmm.2011.714.

\section{Potential of miR-101 and miR-744 as diagnostic biomarker for NPC}

The ROC curve analysis, as shown in Figure 2 and Table 5, showed that miR-101 has area under curve (AUC) of 0.654 (95\% CI: 0.465 - 0.844) while miR-744 has AUC of 0.588 (95\% CI: 0.368 0.808).

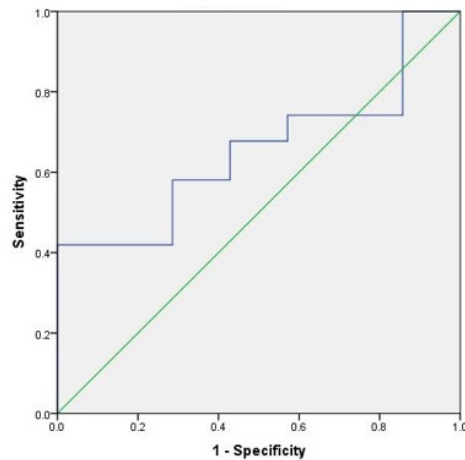

b)

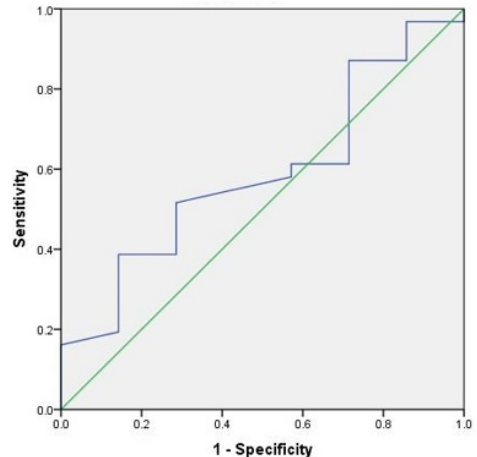

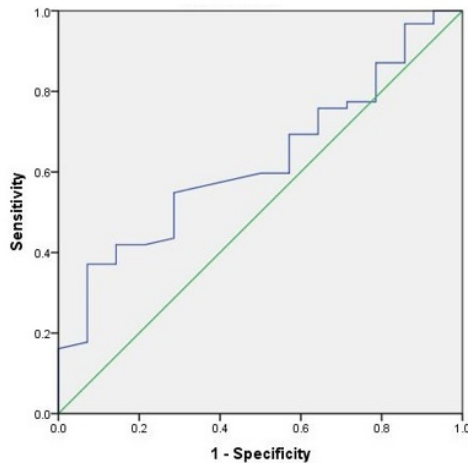

Figure 2 ROC curve analysis for a) miR-101, b) miR-744 and c) combination of mIR-101 and miR-744.

Table 5 AUC for miR-101 and miR-744, and combination of miR-101 and miR-744.

\begin{tabular}{cc}
\hline Target & AUC \\
\hline miR-101 & $0.654(95 \%$ CI: $0.465-0.844)$ \\
miR-744 & $0.588(95 \%$ CI: $0.368-0.808)$ \\
miR-744 and miR-101 & $0.626(95 \%$ CI: $0.481-0.771)$ \\
\hline
\end{tabular}

\section{Discussion}

Several studies to profile the signature of miRNA expression in NPC have been previously reported $[16,26,27]$. Recognizing that the signature of miRNA expression in a disease may provide preliminary information on the behaviour of the disease including in cancers, we evaluated the expression profiles of miR-101 and miR-744 among Malaysian patients with NPC. In Malaysia, so far, there was one published study by Nurul-Syakima et al. [25] that profiled the miRNA expression in head and neck cancers using human biopsies, in which NPC biopsies were included. However, detailed analyses in that study was only limited to investigate the roles of miRNAs in HSCC, excluding the NPC $[28,29]$. In this study, we took the initiative to determine the expression of miR-101 and miR-744, the miRNAs that were found to be 
http://wjst.wu.ac.th

differentially expressed in the study by Nurul-Syakima et al. [25], in NPC biopsies and analyse statistically on their performance to be biomarkers for NPC.

In order to observe whether the expression of miR-101 and miR-744 in HNSCC samples from the previous study were the same as in NPC samples, the current study was attempted to use the same chemistry for detection (used of SYBR Green) and endogenous control (used of SNORD48) to produce a comparable finding. As the samples in the current study were collected from the archive with limited number and type of nasopharynx samples, some inevitable differences existed between the current and previous study, which were clinical material (formalin instead of RNAlater fixation) and type of tissues used for non-NPC control group (normal, lymphoma and inflammation instead of normal only). Even though the clinical material used in the current study was slightly different with the previous study, several studies showed that miRNA expression in FFPE samples was highly correlated to miRNA expression in fresh frozen samples, which is comparable to RNAlater fixed samples [28-30]. Another study by Vojtechova et al. [33] could not find a better correlation values of miRNA expression profiles in fresh frozen with FFPE samples. This indicated a similarity in the pattern of miRNA expression between fresh frozen with FFPE samples. Furthermore, Torres et al. [34] have demonstrated that SNORD48 was among the most stable endogenous control in FFPE samples. This body of evidences supported that the usage of FFPE samples with SNORD48 as endogenous control in current study shall give a comparable result with the study by Nurul-Syakima et al. [25]. For the issue of different type of tissues used for nonNPC control group, our analysis, as shown in Table 6, demonstrated no changes in terms of trend of miRNA expression as compared to the results obtained in the study by Nurul Syakima et al. [23]. Moreover, the inclusion of other non-NPC tissues, which were lymphoma and inflammatory tissues, into non-NPC control group did give better p-value as compared to the non-NPC control group with normal tissue only. Therefore, the differences presented in the current study still made the study comparable to the previous study.

Table 6 The results of gene expression and p-value of miR-101 and miR-744 for non-NPC controls with normal, inflammation and lymphoma tissues and non-NPC controls with normal tissue only.

\begin{tabular}{|c|c|c|c|c|}
\hline \multirow{2}{*}{ Target } & \multicolumn{2}{|c|}{ Non-NPC controls with normal, inflammation and lymphoma } & \multicolumn{2}{|c|}{ Non-NPC controls with normal only } \\
\hline & Fold-change & p-value ${ }^{a}$ & Fold-change & p-value ${ }^{a}$ \\
\hline miR-101 & -1.39 & 0.039 & -1.26 & 0.241 \\
\hline miR-744 & 2.48 & 0.232 & 1.41 & 0.717 \\
\hline
\end{tabular}

${ }^{a} \mathrm{p}$-value based on independent $t$-test.

There was lack of miRNA profiling studies that reported the down-regulation and up-regulation of miR-101 and miR-744 in NPC, respectively. Most of the studies focused on the role and prognostic value of these miRNAs in NPC [18,21-24]. Intriguingly, these studies reported the consistent finding regarding the trend of expression of these miRNAs. The miRNA profiling study by Nurul-Syakima et al. [25] has reported the down-regulation and up-regulation of miR-101 and miR-744, respectively, in HNSCC tissues where NPC biopsies were included in the studied samples. The current study has been successful to obtain the same differential expression of miR-101 and miR-744 as in the study by Nurul-Syakima et al. [25] and supported the earlier notion on the utility of miRNAs as biomarkers for HNSCC. However, since the panel of miRNAs found by Nurul-Syakima et al. [25] was based on a wide range of tumour sites including buccal, supraglottic, nasopharyngeal, retromolar, and at the external ear and nasal cavity, the panel could not tell the specific site of the cancer. Identification of specific miRNA expression signature that can distinguish the HNSCC of specific sites could make the panel more meaningful. 
http://wjst.wu.ac.th

We continued the assessment by observing the sensitivity and specificity of miR-101 and miR-744 to distinguish between NPC and non-NPC cases. The prognostic performance of miR-101 and miR-744 in NPC have been described experimentally and statistically in previous studies [24,27]. To the best of our knowledge, our study was the first study that reported the diagnostic performance of miR-101 and miR-744 for the detection of NPC. Using ROC curve analysis, we found that miR-101 has AUC of 0.654 to discriminate NPC from non-NPC control subjects while miR-744 has AUC of 0.588 and combination of miR-101 and miR-744 has AUC of 0.626. Even though the AUC of both miRNAs were quite low, the AUCs were still above the minimum value, which was 0.5 [35]. Hajian-Tilaki has discussed several issues that can over- or under-estimate the result of the ROC curve analysis [35]. Among the issue was confounder such as incomparable age between case and non-NPC control group. To reduce the confounder effects, we re-analysed the AUC of these miRNAs but with a reduction on the sample size to produce a set of sample population with matched demographical characteristics between NPC and nonNPC controls. The reduction of the sample size was due to the limited number of non-NPC control samples to be matched with NPC samples. We have performed the ROC curve analysis using sample size of 7 samples per group where the NPC and non-NPC samples were matched for their age and gender. The AUC of miR-101 has slightly decreased to 0.653 but AUC of miR-744 and combination of miR-101 and miR-744 has increased to 0.827 and 0.758 , respectively, as compared to their AUC with complete set of samples. Then, when we performed the ROC curve analysis using sample size of 6 samples per group where the NPC and non-NPC samples were matched for their age, gender, and ethnicity, we found that the AUC for miR-101 has reduced to 0.611 as compared to the AUC with complete set of samples but the AUC for miR-744 and combination of miR-101 and miR-744 have increased to 0.792 and 0.726 , respectively. The comparison of different AUC of miR-101, miR-744, and combination of miR-101 and miR-744 in different sample size is shown in Table 7. Here, we were in agreement with the conclusion of Hajian-Tilaki [35] that to obtain a reliable result from ROC curve analysis, the study should be properly designed with a broad spectrum of cases and controls, prevention of bias, and control of confounders. This statement was supported by other studies that showed the large and balance sample size between case and control group yielded better AUC in discriminating cases from the control group [36,37].

Table 7 Comparison of AUC of miR-101, miR-744 and combination of miR-101 and miR-744 in different sample size.

\begin{tabular}{|c|c|c|c|}
\hline \multirow{2}{*}{ Sample size } & \multicolumn{3}{|c|}{ AUC } \\
\hline & miR-101 & miR-744 & miR-101 and miR-744 \\
\hline $31 \mathrm{NPC} v s .7$ non-NPC controls & 0.654 & 0.588 & 0.626 \\
\hline (Whole study population) & (95 \% CI: $0.465-0.844)$ & (95 \% CI: $0.368-0.808)$ & (95 \% CI: $0.481-0.771)$ \\
\hline 7 NPC vs. 7 non-NPC controls & 0.653 & 0.827 & 0.758 \\
\hline (Age- and gender-matched) & (95 \% CI: $0.347-0.959)$ & (95 \% CI: $0.601-1.000)$ & (95 \% CI: $0.576-0.939)$ \\
\hline 6 NPC vs. 6 non-NPC controls & 0.611 & 0.792 & 0.726 \\
\hline (Age-, gender- and ethnicity-matched) & (95 \% CI: $0.271-0.952)$ & (95 \% CI: $0.528-1.000)$ & (95 \% CI: $0.521-0.930)$ \\
\hline
\end{tabular}

There were limitations in the current study that need to be considered and improved on in the future to produce more reliable and significant results. Sample size, especially for non-NPC control group, need to be increased and balanced with NPC group to ensure that all NPC samples can be matched accordingly to their age, gender, and ethnicity. Type of tissues used for controls also need to be carefully considered to ensure the result obtained reflects the real biological phenomena. Despite some limitations, the study could provide supportive evidence for the differential expression and performance as diagnostic biomarkers for miR-101 and miR-744. 
http://wjst.wu.ac.th

\section{Conclusions}

As a conclusion, this study has successfully demonstrated the differential expression of miR-101 and miR-744 in NPC as compared to non-NPC controls. Even though we able to determine the differential expression of both miRNAs, the performance of these miRNAs in discriminating NPC from non-NPC control group could be improved in the future by designing a study with large and balanced sample size between NPC and non-NPC control groups. Since we used FFPE samples, tissue homogeneity is another concern to consider as the surrounding tissue could affect the miRNA expression and contribute to confounder effect. This confounder effect can be prevented by performing macrodissection on the FFPE samples [32].

\section{Acknowledgement}

This study was supported by Research Initiative Grant Scheme (RIGS15-079-0079) of IIUM and Fundamental Research Grant Scheme (FRGS15-237-0478 and FRGS16-064-0563) of Ministry of Higher Education of Malaysia. We would also like to thank Central Research and Animal Facility, Kulliyyah of Science, IIUM for allowing us to do our laboratory works in their facility.

\section{References}

[1] M Azizah Ab, IT Nor Saleha, A Noor Hashimah, ZA, Azmah and W Mastulu. Malaysian National Cancer Registry Report 2007-2011. Ministry of Health, Malaysia. Available at: http://nci.moh.gov.my/index.php/en/announcement/340-malaysian-national-cancer-registry-report2007-2011, accessed January 2018.

[2] BCR Devi, P Pisani, TS Tang and DM Parkin. High incidence of nasopharyngeal cancer carcinoma in Native People of Sarawak, Borneo Island. Epidemiol. Biomarkers Prev. 2004; 13, 482-6.

[3] GCC Lim, S Rampal and Y Halimah. Cancer Incidence in Peninsular Malaysia, 2003-2005. The Third Report of the National Cancer Registry Malaysia. Ministry of Health, Malaysia. Available at: http://www.moh.gov.my/images/gallery/Report/Cancer/CancerIncidenceinPeninsularMalaysia20032005x1x.pdf, accessed January 2018.

[4] K Breving and A Esquela-Krescher. The complexities of microRNA regulation: Mirandering around the rules. Int. J. Biochem. Cell Biol. 2006; 42, 1316-29.

[5] R Schickel, B Boyerinas, SM Park and ME Peter. MicroRNAs: Key players in the immune system, differentiation, tumorigenesis and cell death. Oncogene 2008; 27, 5959-74.

[6] A Esquela-Krescher and FJ Slack. Oncomirs-microRNA with a role in cancer. Nat. Rev. Cancer 2006; 6, 259-69.

[7] S Pfeffer and O Voinnet. Viruses, microRNAs and cancer. Oncogene 2006; 25, 6211-9.

[8] SK Shenouda and SK Alahari. MicroRNA function in cancer: Oncogene or a tumor suppressor? Cancer Metastasis Rev. 2009; 28, 369-78.

[9] T Spence, J Bruce, KW Yip and FF Liu. MicroRNAs in nasopharyngeal carcinoma. Chin. Clin. Oncol. 2016; 5, 17.

[10] J Lu, H Luo, X Liu, Y Peng, B Zhang, L Wang, X Xu, X Peng, G Li, W Tian, ML He, H Kung and XP Li. miR-9 targets CXCR4 and functions as a potential tumor suppressor in nasopharyngeal carcinoma. Carcinogenesis 2014; 35, 554-63.

[11] K Cai, Y Wan, G Sun, L Shi, X Bao and Z Wang. Let-7a inhibits proliferation and induces apoptosis by targeting EZH2 in nasopharyngeal carcinoma cells. Oncol. Rep. 2012; 28, 2101-6.

[12] N Liu, LL Tang, Y Sun, RX Cui, HY Wang, BJ Huang, QM He, W Jiang and J Ma. MiR-29c suppresses invasion and metastasis by targeting TIAM1 in nasopharyngeal carcinoma. Cancer Lett. 2013; 329, 181-8.

[13] JX Zhang, D Qian, FW Wang, DZ Liao, JH Wei, ZT Tong, J Fu, XX Huang, YJ Liao, HX Deng, YX Zeng, D Xie and SJ Mai. MicroRNA-29c enhances the sensitivities of human nasopharyngeal carcinoma to cisplatin-based chemotherapy and radiotherapy. Cancer Lett. 2013; 329, 91-8. 
http://wjst.wu.ac.th

[14] EY Choy, KL Siu, KH Kok, RW Lung, CM Tsang, KF To, DL Kwong, SW Tsao and DY Jin. An Epstein-Barr virus-encoded microRNA targets PUMA to promote host cell survival. J. Exp. Med. 2008; 205, 2551-60.

[15] L Dölken, G Malterer, S Erhard, S Kothe, CC Friedel, G Suffert, L Marcinowski, N Motsch, S Barth, M Beitzinger, D Lieber, SM Bailer, R Hoffmann, Z Ruzsics, E Kremmer, S Pfeffer, R Zimmer, UH Koszinowski, F Grässer, G Meister and J Haas. Systematic analysis of viral and cellular microRNA targets in cells latently infected with human gamma-herpesviruses by RISC immunoprecipitation assay. Cell Host Microbe. 2010; 7, 324-34.

[16] L Cai, Y Ye, Q Jiang, Y Chen, X Lyu, J Li, S Wang, T Liu, H Cai, K Yao, JL Li and X Li. EpsteinBarr virus-encoded microRNA BART1 induces tumour metastasis by regulating PTEN-dependent pathways in nasopharyngeal carcinoma. Nat. Commun. 2015; 6, 7353.

[17] Z Sha, X Zu, N Li, Y Li and D Li. Proto-oncogenic miR-744 is upregulated by transcription factor c-Jun via promoter activation mechanism. Oncotarget 2016; 7, 64977-86.

[18] XR Tang, X Wen, QM He, YQ Li, XY Ren, XJ Yang, J Zhang, YQ Wang, J Ma and N Liu. MicroRNA-101 inhibits invasion and angiogenesis through targeting ITGA3 and its systemic delivery inhibits lung metastasis in nasopharyngeal carcinoma. Cell Death Dis. 2017; 8, e2566.

[19] S Chen, H Wang, WL Ng, WJ, Curran and Y Wang. Radiosensitizing effects of ectopic miR-101 on non-small-cell lung cancer cells depend on the endogenous miR-101 level. Int. J. Radiat. Oncol. Biol. Phys. 2011; 81, 1525-9.

[20] NM Alajez, W Shi, ABY Hui, J Bruce, M Lenarduzzi, E Ito, S Yue, BO Sullivan and FF Liu. Enhancer of Zeste homolog 2 (EZH2) is overexpressed in recurrent nasopharyngeal carcinoma and is regulated by miR-26a, miR-101 and miR-98. Cell Death Dis. 2010; 1, e85.

[21] Q Sun, T Liu, T Zhang, S Du, GX Xie, X Lin, L Chen and Y Yuan. MiR-101 sensitizes human nasopharyngeal carcinoma cells to radiation by targeting stathmin 1. Mol. Med. Rep. 2015; 11, 3330-6.

[22] Y Fang, X Zhu, J Wang, N Li, D Li, N Sakib, Z Sha and W Song. MiR-744 functions as a protooncogene in nasopharyngeal carcinoma progression and metastasis via transcriptional control of ARHGAP5. Oncotarget 2015; 6, 13164-75.

[23] Z Sha, X Zhu, N Li, Y Li and D Li. Proto-oncogenic miR-744 is up-regulated by transcription factor c-Jun via a promoter activation mechanism. Oncotarget 2016; 7, 64977-86.

[24] Q Yu, F Zhang, Z Du and Y Xiang. Up-regulation of serum miR-744 predicts poor prognosis in patients with nasopharyngeal carcinoma. Int. J. Clin. Exp. Med. 2015; 8, 13296-302.

[25] AM Nurul-Syakima, C Yoke-Kqueen, AR Sabariah, MS Shiran, A Singh and L Learn-Han. Differential microRNA expression and identification of putative microRNA targets and pathways in head and neck cancers. Int. J. Mol. Med. 2011; 28, 327-36.

[26] T Li, JX Chen, XP Fu, S Yang, Z Zhang, KhH Chen and Y Li. microRNA expression profiling of nasopharyngeal carcinoma. Oncol. Rep. 2011; 25, 1353-63.

[27] N Liu, NY Chen, RX Cui, WF Li, Y Li, RR Wei, MY Zhang, Y Sun, BJ Huang, M Chen, QN He, N Jiang, L Chen, WC Cho, JP Yun, J Zeng, LZ Liu, L Li, Y Guo, HY Wang and J Ma. Prognostic value of a microRNA signature in nasopharyngeal carcinoma: A microRNA expression analysis. Lancet Oncol. 2012; 13, 633-41.

[28] N-SA Mutalib, L Learn-Han, SM Sidik, SA Rahman, ASM Singh. And C Yoke-Kqueen. miR-181a regulates multiple pathways in hypopharyngeal squamous cell carcinoma. Afr. J. Biotechnol. 2012; 11, 6129-37.

[29] YK Cheah, RW Cheng, SK Yeap, CH Khoo and HS See. Analysis of TP53 gene expression and p53 level of human hypopharyngeal FaDu (HTB-43) head and neck cancer cell line after microRNA181a inhibition. Genet. Mol. Res. 2014; 13, 1679-83.

[30] AB Hui, W Shi, PC Boutros, N Miller, M Pintilie, T Fyles, D McCready, D Wong, K Gerster, L Waldron, I Jurisica, L Penn and FF Liu. Robust global micro-RNA profiling with formalin-fixed paraffin-embedded breast cancer tissues. Lab. Invest. 2009; 89, 597-606.

[31] RS Goswami, L Waldron, J Machado, NK Cervigne, W Xu, PP Reis, DJ Bailey, L Jurisica, MR Crump and S Kamel-Reid. Optimization and analysis of a quantitative real-time PCR-based 
http://wjst.wu.ac.th

technique to determine microRNA expression in formalin-fixed paraffin-embedded samples. $B M C$ Biotechnol. 2010; 10, 47.

[32] S Romero-Cordoba, S Rodriguez-Cuevas, R Rebollar-Vega, V Quintanar-Jurado, A Maffuz-Aziz, G Jimenez-Sanchez, V Bautista-Piňa, R Arellano-Llamas and A Hidalgo-Miranda. Identification and pathway analysis of microRNAs with no previous involvement in breast cancer. PloS One 2012; 7, e31904.

[33] Z Vojtechova, J Zavadil, J Klozar, M Grega and R Tachezy. Comparison of the miRNA expression profiles in fresh frozen and formalin-fixed paraffin-embedded tonsillar tumors. PloS One 2017; 12, e0179645.

[34] A Torres, K Torres, P Wdowiak, T Paszkowski and R Maciejewski. Selection and validation of endogenous controls for microRNA expression studies in endometrioid endometrial cancer tissues. Gynecol. Oncol. 2013; 130, 588-94.

[35] K Hajian-Tilaki. Receiver Operating Characteristic (ROC) curve analysis for medical diagnostic test evaluation. Caspian J. Intern. Med. 2013; 4, 627-35.

[36] J Wang, JT Yu, L Tan, Y Tian, J Ma, CC Tan, HF Wang, Y Liu, MS Tan, T Jiang and L Tan. Genome-wide circulating microRNA expression profiling indicates biomarkers for epilepsy. Sci. Rep. 2015; 5, 9522.

[37] MB Wozniak, G Scelo, DC Muller, A Mukeria, D Zaridze and P Brennan. Circulating microRNAs as non-invasive biomarkers for early detection of non-small-cell lung cancer. PloS One 2015; 10, e0125026. 